\title{
Comparative assessment of two proxies of fish discard survival
}

\author{
Morfin Marie ${ }^{1,{ }^{\star}}$, Kopp Dorothee ${ }^{1}$, Benoît Hugues P. ${ }^{2}$, Méhault Sonia ${ }^{1}$ \\ ${ }^{1}$ IFREMER, Unité de Sciences et Technologies halieutiques, Laboratoire de Technologie et Biologie \\ Halieutique, 8 rue François Toullec, F-56100 Lorient, France \\ ${ }^{2}$ Fisheries and Oceans Canada, Maurice Lamontagne Institute, Mont Joli, QC G5H 3Z4, Canada \\ *Corresponding author : Marie Morfin, email address : $\underline{\text { mmorfin@ifremer.fr }}$
}

\begin{abstract}
:
Two vitality index approaches have been demonstrated to be good proxies of discard survival in similar fishing and environmental conditions: Reflex Action Mortality Predictors combined with injuries (RI) scores that measure the proportion of impaired reflexes and injuries, and a simpler, quicker, but less precise approach based on ordinal categories related to fish body movements and injuries (semiquantitative assessment, SQA). This study assessed and compared these two approaches for five species (two flatfishes, skates, a seabass and a catshark) discarded in a coastal otter trawl fishery in the Bay of Biscay. All species displayed good vitality status according to both indices and were not very sensitive to the fishing nor their biological conditions. Still, flatfishes were more sensitive to discarding while the catshark was very resistant. Furthermore, depending on species, the impairment of some reflexes and injuries were associated to stressing factors, highlighting the potential of the approach but also the complexity involved in building a relevant score. The SQA index was highly correlated with the $\mathrm{RI}$ score and was sensitive to more sources of stressing factors for similar predictive performance. While the relevance of these two approaches should be ultimately determined by the strength and consistency of their association with discard survival, these results suggest that the RI approach was not more effective than SQA despite the extra labour and time involved in collecting the data.
\end{abstract}

\section{Highlights}

The two most used vitality indices of fish discard survival are very correlated. Some redundancies and inconsistencies were detected within one of the indices. Both indices responded similarly to stressing factors. One of the indices is deemed superior given the ease of data collection.

Keywords : Discard survival, Vitality indicators, Reflex Action Mortality Predictor, Bay of Biscay, Coastal otter trawl fishery 


\section{INTRODUCTION}

30 The European Union has enacted a Landing Obligation under which discarding of species under quota management will be prohibited for all fisheries by 2019 (European Commission, 2013). However, the regulation allows for exemptions for 'species for which scientific evidence demonstrates high survival rates, taking into account the characteristics of the gear, fishing practices and the ecosystem" (article 15 paragraph 4(b)). In this context, there has been a recent increase in research in Europe aimed at providing accurate assessment of discarded fish survival and identifying associated stressors (Breen et al., 2012; Depestele et al., 2014; Mérillet et al., 2018; Morfin et al., 2017a; UhImann et al., 2016).

There are constraints associated with all approaches for estimating discard mortality rates, including important logistical and financial investments. Captivity studies cannot fully replicate the conditions experienced by discarded fish, for example, excluding discard-related predation mortality and potentially inducing mortality that would not occur in situ (Raby et al., 2014). Mark and recapture tagging is only possible as part of a substantial and ongoing tagging programme, while data storage and acoustic tags offer alternative methods that are generally expensive and only suitable for larger specimens owing to the current size of the tags (Capizzano et al., 2016; Yergey et al., 2012). Given these constraints, experiments can be unfeasible, for example in small-scale fisheries where discard composition may be very diversified.

To overcome these experimental difficulties, indicators of fish survival potential (hereafter vitality) based on external visual signs of fish health and vigor at the time of discarding were developed. They are often integrated into these assessments as they are rapid and uncostly to measure in the field, thus enabling the collection of large samples in a wide variety of external conditions. Vitality indicators can be used to estimate the discard mortality rate representative of a fishery after initial calibration with mortality data (Benoit et al., 2012; Morfin et al., 2017a). They can also be used to explore the potential influence of the fishing conditions on fish survival to propose mitigation measures, or to extrapolate the vitality index at a larger scale (e.g. fleet), using the fishing conditions as predictors (Benoît et al., 2010, 2012).

53 The 'Reflex Action Mortality Predictor' (RAMP) approach (Davis, 2010) is commonly used as a discard 54 survival indicator in fish and shellfish (e.g., Barkley and Cadrin, 2012; Methling et al., 2017; Raby et al., 2012; Uhlmann et al., 2016; Yochum et al., 2015). The approach consists in evaluating the impairment, in individual fish, of reflexes associated with essential functions (such as respiration, swimming and escaping predators). As different sources of stress may affect reflex responses in different ways, a combination of reflexes is evaluated and combined in a single impairment score. Furthermore, some studies also 
integrated the presence of injuries in a RAMP combined with an injury (RI) score, to strengthen the mortality prediction (Campbell et al., 2009; Nguyen et al., 2014; Uhlmann et al., 2016).

61 An alternative approach is the use of a semi-quantitative index (SQA) of individual fish vitality (e.g., Benoît

62 et al., 2010). Ordinal categories are defined according to the degree of visible injuries and the vigor of body

63 movements. As the scoring is based on a rapid (3-10 seconds) visual and tactile assessment by observers,

64 it is possible to sample a larger number of fish than with RAMPs and injury scoring, which requires roughly 65 the same time to assess each reflex and injury. The SQA approach also involves less manipulation of 66 individual fish, which itself can induce additional stress. Studies using the SQA approach typically employ

67 three to five vitality categories, ranging from fish that are barely injured and very vigorous to seriously 68 injured or moribund fish. SQA scores have been demonstrated to be a relevant proxy of survival in tagging69 recapture and holding studies, and for a diversity of fish and shellfish taxa (Benoît et al., 2012; Braccini et 70 al., 2012; Enever et al., 2009; Hueter and Manire, 1994; Mérillet et al., 2017; Morfin et al., 2017a; Ridgway 71 et al., 2006; Van Beek et al., 1990).

72 Though both RI and SQA vitality indices are demonstrated accurate proxies of discard survival, their 73 properties have never been compared directly. Here we measured a combination of reflexes and injuries 74 and a SQA index on the same individuals for five species discarded in a coastal otter trawl fishery to achieve 75 the following objectives. First, we evaluated the responses of each reflex and injury to determine the extent to which their score is a consistent and coherent vitality indicator. Second, we assessed the relationship between the RI score and the SQA index. Third, we compared the responses of both vitality indices to common stressors. Based on these results, we discussed the relative merits of these two approaches.

\section{MATERIAL \& METHODS}

\subsection{At-sea experiment}

82 The vitality of fish discarded in commercial conditions was sampled by two observers on-board a $10.95 \mathrm{~m}$ 83 long French coastal trawler operating in the Bay of Biscay (ICES subarea VIIla) and targeting multispecies 84 fish assemblages. The vessel had an engine power of $150 \mathrm{~kW}$ and was rigged with a single bottom trawl 85 with a $20 \mathrm{~m}$ headline and a $70 \mathrm{~mm}$ diamond mesh codend. Two sets of trials were conducted during five 86 day-trips in July 2014 (27 hauls) and in March 2015 (31 hauls). Discarded fish were randomly sampled once 87 the catch sorting began and for a maximum time period of 46 minutes so that the duration of air exposure of fish was representative of the commercial fishing practices. 
89 A series of variables related to the fishing operation and associated environmental conditions were 90 recorded (Table 1): the presence of a tickler chain on the trawl for some hauls, the total handling time 91 (from codend retrieval to when the fish was assessed for vitality status, in minutes), the tow duration 92 ( $\mathrm{min}$ ), the average tow depth $(\mathrm{m})$, the catch weight (in number of crates, $\sim 45 \mathrm{~kg}$ each), the presence of 93 injury-inducing elements in the catch such as stones, crabs, sea urchins, cuttlefish ink, mud and algae, and 94 the air and bottom-water temperatures from which the difference $\left({ }^{\circ} \mathrm{C}\right)$ was calculated as an index of 95 thermal shock experienced by fish during gear retrieval.

96 At the moment they would normally be released to the sea, each specimen was first rapidly assessed ( $\sim 5$ 97 sec.) according to the SQA index, measured in TL (cm), and then assessed for RI ( $45 \mathrm{sec}$.) (Table 2). This 98 order of observation was chosen because the SQA observation period was deemed sufficiently short not 99 to affect the RI observation, whereas this may not be the case for the reverse. This study focusses on five 100 species: European seabass (Dicentrarchus labrax), small-spotted catshark (Scyliorhinus canicula), 101 European plaice (Pleuronectes platessa), skates (Rajidae family) and common sole (Solea solea), 102 referenced hereafter as seabass, catshark, plaice, skates and sole.

103

\begin{tabular}{|c|c|c|c|c|c|c|}
\hline & & Plaice & Skates & Sole & Seabass & Catshark \\
\hline \multirow[t]{2}{*}{$\mathrm{Nb}$ ind. / hauls } & March & $195 / 26$ & $107 / 18$ & $57 / 20$ & $240 / 23$ & $29 / 11$ \\
\hline & July & $145 / 20$ & $231 / 21$ & $66 / 21$ & 93 / 12 & $23 / 9$ \\
\hline \multirow[t]{2}{*}{ Depth (m) } & March & $16(7.6)$ & $20(7.6)$ & $11(3.7)$ & $8(3.0)$ & $20(5.6)$ \\
\hline & July & $23(7.1)$ & $25(6.2)$ & $24(6.5)$ & 15 (3.9) & $25(4.3)$ \\
\hline \multirow[t]{2}{*}{ Air temperature $\left({ }^{\circ} \mathrm{C}\right)$} & March & 11 (1.9) & $12(2.2)$ & $10(1.4)$ & 11 (1.9) & $11(2.7)$ \\
\hline & July & $22(2.6)$ & $22(2.2)$ & $22(2.5)$ & $22(2.5)$ & $21(3.7)$ \\
\hline \multirow[t]{2}{*}{ Thermal shock $\left({ }^{\circ} \mathrm{C}\right)$} & March & $2(1.3)$ & $2.3(1.5)$ & $1(2.9)$ & $2(1.2)$ & $2.3(1.7)$ \\
\hline & July & $8(3.0)$ & $8(2.6)$ & $8(0.8)$ & $5(1.3)$ & $8(4.0)$ \\
\hline \multirow[t]{2}{*}{ Tow duration (min) } & March & $106(25.1)$ & $105(21.2)$ & 98 (29.9) & $84(23.8)$ & $106(18.1)$ \\
\hline & July & $114(23.2)$ & $120(19.6)$ & $109(25.9)$ & $103(27.9)$ & $122(22.3)$ \\
\hline \multirow[t]{2}{*}{ Thickler chain $(0 / 1)$} & March & $0.23(0.4)$ & $0.33(0.47)$ & $0(0)$ & $0.004(0.1)$ & $0.38(0.49)$ \\
\hline & July & $0.54(0.5)$ & $0.65(0.5)$ & $0.61(0.5)$ & $0(0)$ & $0.7(0.5)$ \\
\hline \multirow[t]{2}{*}{ Catch (crates) } & March & 4.5 (1.9) & $3.9(1.9)$ & $8(4.5)$ & $6.2(1.5)$ & $3.9(0.95)$ \\
\hline & July & $5.4(1.2)$ & $5.4(1.8)$ & $5.5(1.8)$ & $5.7(1.6)$ & $7.0(2.2)$ \\
\hline \multirow[t]{2}{*}{ Air exposure (min) } & March & $18(8.9)$ & $17(9.1)$ & $20(10.5)$ & $18(8.1)$ & $14(6.6)$ \\
\hline & July & $20(8.7)$ & $17(9.5)$ & $19(8.5)$ & $16(8.7)$ & $22(9.0)$ \\
\hline
\end{tabular}




\begin{tabular}{lllllll}
\hline TL $(\mathrm{cm})$ & March & $25(2.6)$ & $39(12.6)$ & $18(5.4)$ & $27(4.0)$ & $51(5.1)$ \\
& July & $24(3.0)$ & $38(9.2)$ & $21(2.6)$ & $31(3.0)$ & $51(6.4)$ \\
& & & & & & \\
Injury-inducing & March & $0.03(0.4)$ & $0.01(0.1)$ & $0.35(0.5)$ & $0.2(0.4)$ & $0.07(0.26)$ \\
elements (0/1) & July & $0.21(0.2)$ & $0.31(0.5)$ & $0.27(0.5)$ & $0.03(0.2)$ & $0.6(0.5)$ \\
\hline
\end{tabular}

Table 1. Sample size (number of individuals / number of hauls) and mean fishing conditions with standard deviation in parenthesis by species and season for the sampled trips.

\subsection{Collection of vitality indices}

The reflexes were chosen according to preliminary tests on acclimated individuals and their relevance for vitality assessment in the literature (Humborstad et al., 2009; ICES, 2014; Raby et al., 2012; Uhlmann et al., 2016). Finally, fixe reflexes were tested on the five species: (1) Body flex, (2) Escape, (3) Startle Touch, (4) Righting and (5) Respiration (Table 2). Each reflex was recorded as 'unimpaired' if there was no doubt about the fish response, and 'impaired' if there was a doubt about it, or if it was weak or absent. Three classes of injuries were recorded, with two major ones related to barotrauma (exophthalmia and stomach reversion) and the third covering all other injuries (e.g. bleeding, scale loss). A RI score was established for each individual as the proportion of impaired reflexes and presence of injuries in each class, and any deviation of the score compared to healthy individuals was considered as a loss of vitality (as per Davis, 2010). The SQA index was defined by four ordinal categories based on fish general activity and injuries: i) Excellent: Vigorous body movement, no or minor external injuries; ii) Good: Moderate body movement, no or minor external injuries; iii) Poor: Weak body movement or substantial injuries, iv) Moribund: No body or head complex movements (adapted from Benoît et al., 2010).

\begin{tabular}{ll}
\hline Reflex & \multicolumn{1}{c}{ Description } \\
\hline Body flex & Fish actively tries to move head and tail when held outside the water on the palm of a hand \\
\hline Escape & Fish tries to escape when it is held gently between two fingers \\
Startle touch & Fish moves when hand approaches to touch it under water \\
Righting & Fish flips back around or attempts when turned upside down in the water \\
Respiration & Operculum or spiracle movement \\
Injury & \\
\hline Reversion & Stomach or cloaca reversion observed \\
Exophthalmia & Exophthalmia observed \\
Other injuries & Scale loss, fin fraying, abrasion, bleeding, wounding, mucus loss
\end{tabular}


Table 2. Description of the measured reflexes and injuries for the RI index.

\subsection{Statistical analysis}

122 To achieve the first objective of this study, we explored the results of the different reflexes and injuries 123 that constitute the RI score, across the five species and both seasons. For each reflex and injury, the 124 difference between seasons was tested by the Fisher's exact test, and the scores were compared using the 125 Kolmogorov-Smirnov test. Then, the consistence of the score was assessed by examining the relationship 126 between the proportion of each reflex impairment and injury, and the RI score in the sample. To achieve the second objective, the distributions of the RI score relatively to the SQA index categories were examined and, as the SQA index is ordinal, the Spearman's rank correlation coefficient was estimated for each species.

The third objective was achieved by looking at the potential influence of factors related to the fishing conditions on fish vitality using a logistic binomial regression for the RI score, and a proportional-odds ordered logit model (Benoît et al., 2010; McCullagh, 1980) to account for the ordinal nature of the SQA index. In both cases, a random effect was tested at the haul level to account for the potential additional variability between hauls. All the linear combinations of covariates as well as the interactions that were felt to potentially be important a priori were tested, i.e. the ones including the interactions with the air exposure. Ordinal models were fitted with the R package 'ordinal' (Christensen, 2015). The random effect was tested on the saturated model including all covariates by a one-tailed chi-square test and the fixed effects selected by AIC. The predictive performance was assessed by a 'leave- $p$-out' cross-validation procedure, where $p=10 \%$ of the sample size, and the prediction error was measured by the Ranked Probability Score (RPS) (Epstein, 1969; Wilks, 2011), appropriate for ordinal response variable. To compare the predictive skills of the different selected models across species and vitality indices, their percentage of predictive enhancement relative to the corresponding constant model (without any covariates) was calculated:

Where $R P S_{S}$ and $R P S_{0}$ are the RPS of the selected model and the constant model respectively.

\section{RESULTS \& DISCUSSION}

3.1. Reflexes and injuries analysis 
For the five species and both seasons, more than $50 \%$ of the individuals had injuries but very few suffered

149 from exophthalmia or stomach reversion (Fig.1). The absence of operculum or spiracle movement was

150 rarely observed, from $0 \%$ for catshark to $10 \%$ for plaice (Fig. 1). The four other reflexes had more 151 intermediate rates of impairment and varied between species, suggesting that the species were unevenly 152 sensitive to the different types of stress, or that the same stress expressed differently from one species to 153 another (Uhlmann et al., 2016). For instance, plaice was less responsive to Body flex than the other species, 154 skates was more sensitive to Righting and Evasion, catshark to Evasion and sole to Righting and Startle 155 Touch. Although the overall distributions of reflexes and injuries were very similar between seasons, 156 especially for catshark, the impairment rates were significantly different for some of the reflexes and 157 injuries (Fig. 1). Seabass was significantly more injured in March, when more injury inducing elements were 158 observed in the trawls (Table 1). These injuries were apparently minor as the reflexes were not more 159 impaired in March. Conversely, the impairment rates for two reflexes were significantly different for skates 160 and sole, but not the injury rate. Plaice displayed the most important variations between seasons, with 161 four reflexes significantly more impaired in July. Surprisingly, its injury rate was more important in March 162 while the presence of injury inducing elements in the trawl was more important in July. The resulting RI 163 scores were significantly different between seasons only for seabass and plaice, and were very low for 164 catshark (less than $10 \%$ on average), followed by sole and seabass (around $20 \%$ on average), and around 165 $38 \%$ for plaice and skates. Although the relationship between the scores and discard survival rate were not established, these results indicate that the vitality of these species was not strongly impacted by these

167 apparently rather favorable fishing conditions (shallow bottoms, short air exposures, light catch weights), 168 in accordance with most of the previous discard survival studies for catshark (Revill et al., 2005; Rodríguez169 Cabello et al., 2005), skates (Depestele et al., 2014; Ellis et al., 2017; Enever et al., 2009; Mandelman et al., 170 2013), seabass (Lewin et al., 2018; Morfin et al., 2017b), plaice and sole (Depestele et al., 2014; Methling 171 et al., 2017; Uhlmann et al., 2016). 

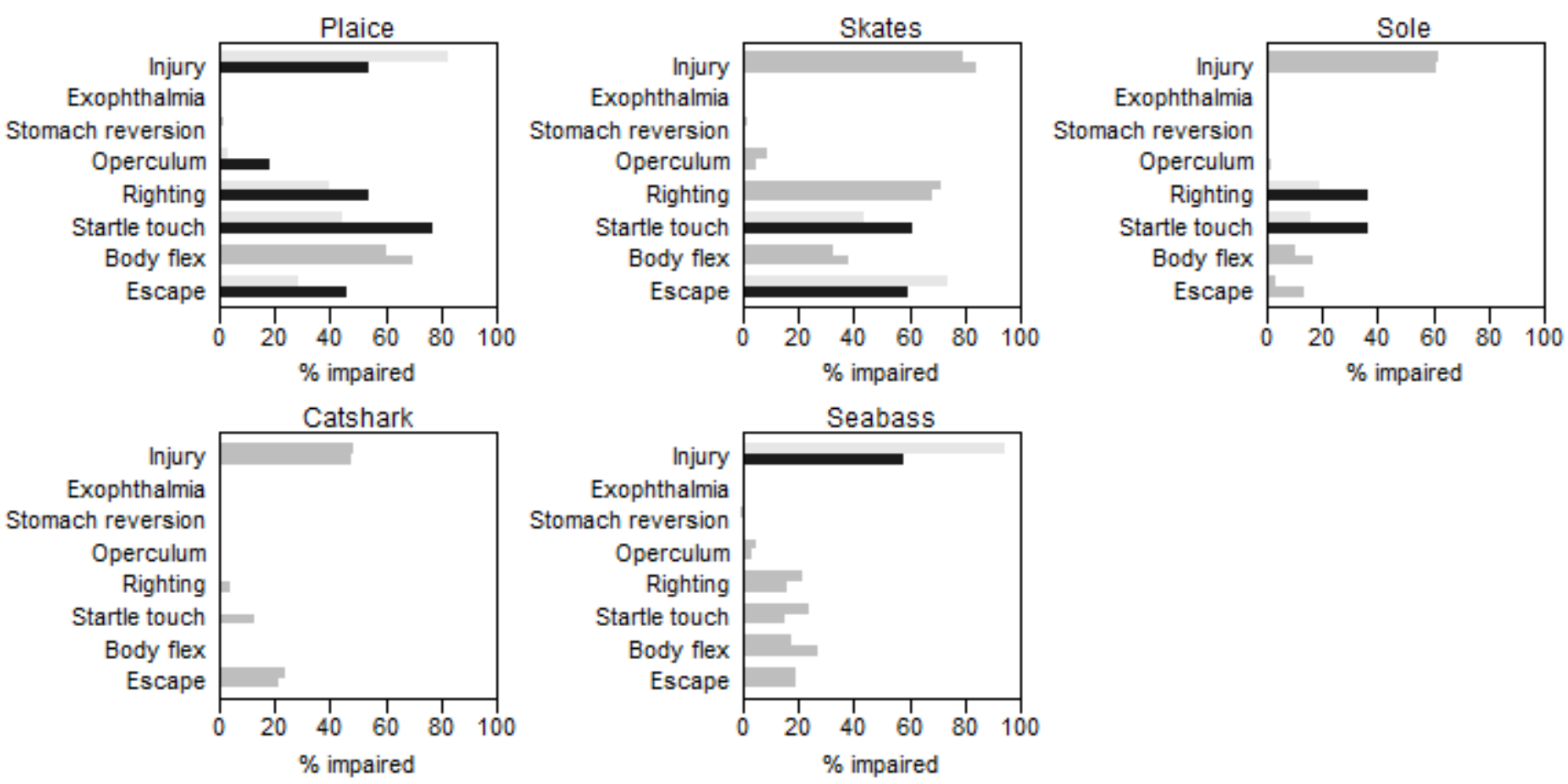

175 Figure 1. Species-specific proportions of impaired reflexes and injury-presence for each season, with the 176 bars for March appearing above those for July for each trait. Bars are coloured according to season when 177 the difference between seasons was significant for a given trait, light grey for March and black for July, 178 and otherwise coloured grey for both seasons.

180 The percent impairment of individual reflexes and injuries generally increased with the RI score, indicating 181 a desirable consistency of response (Fig. 2). The responses for some reflexes were very similar, such as 182 Startle touch and Righting for sole and Startle touch, Righting, Body Flex and Escape for seabass. The rate 183 of impairment of other reflexes only increased for higher levels of the score, suggesting a gradation in the 184 severity of the different reflexes impairment and injuries. For the five species, the injury always caused 185 the initial increase in RI score, i.e., many individuals were injured and were still responsive to reflexes. 186 Note the slight inconsistence of the injury rate with the score for plaice, in accordance with the previous 187 results in Fig. 1, which may be due to the variability of injury severities associated with this variable. 188 Exophthalmia and stomach reversion contributed last and respiration was systematically the last reflex 189 impaired. For the other reflexes, the ranking was species-dependent, Escape/Startle touch/Righting/Body 190 flex for catshark, Body flex/Startle touch/Righting/Escape for plaice and the four reflex curves overlapped 191 for seabass. 


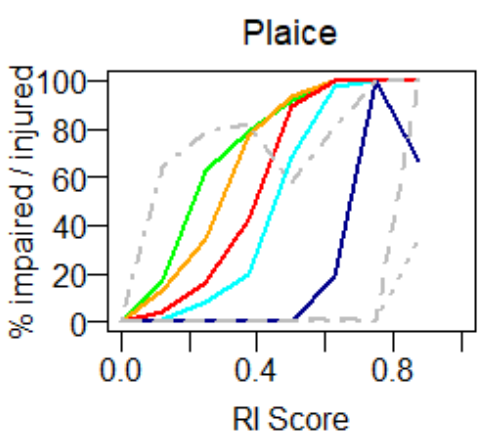

Catshark

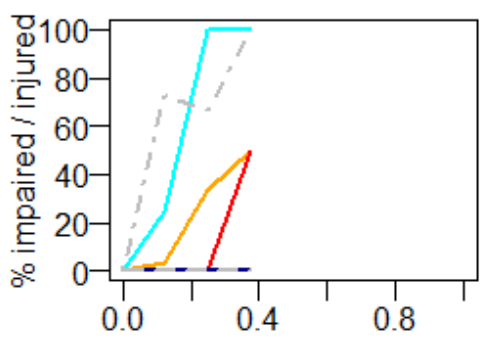

RI Score

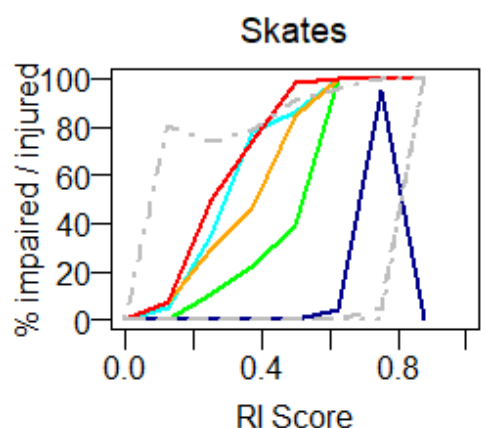

Seabass

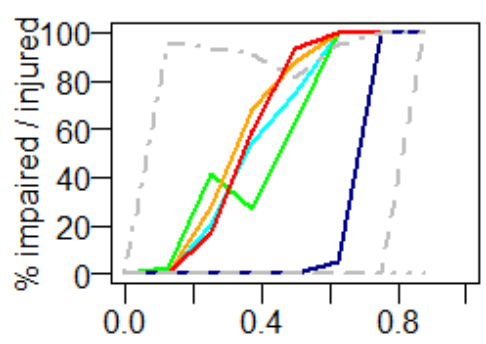

RI Score
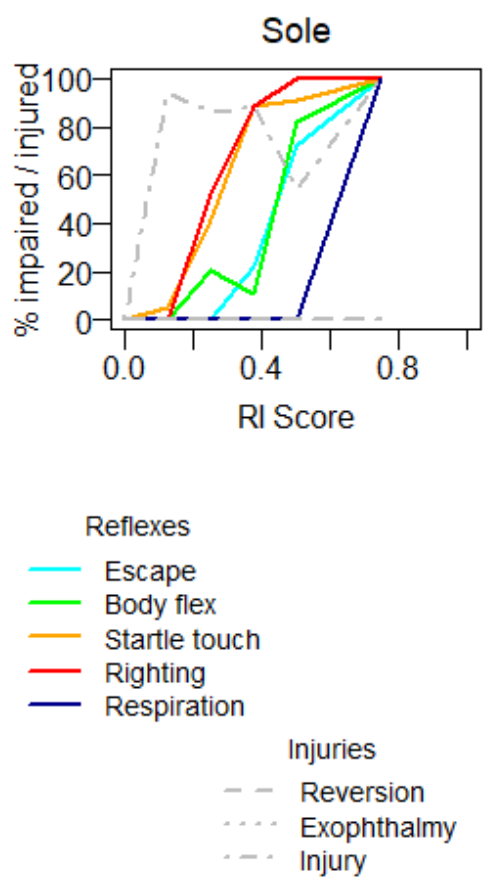

193

194

195

196

197

198

199

200

201

202

203

204

205

Figure 2. Percentage of each reflex impairment and injury depending on the RI score

\subsection{RI score versus SQA index}

According to the SQA index, catshark was in the best condition with 65\% in "Excellent" status, then sole and seabass were mostly categorized in the "Excellent" or "Good" status (67\% and 68\% respectively), while plaice and skates were mostly in "Poor" (56\%, 46\%) and "Good" (30\%, 32\%) status. The distributions among status classes were very similar between seasons as no significant difference was found according to the Fisher's exact test, except for plaice and sole that were in slightly worse conditions in July than in March (Fig. 3). This last result is more consistent than for the RI scores according to the impaired reflexes and injuries reported in the section 3.1., partly because the SQA index makes the distinction between minor and major injuries.
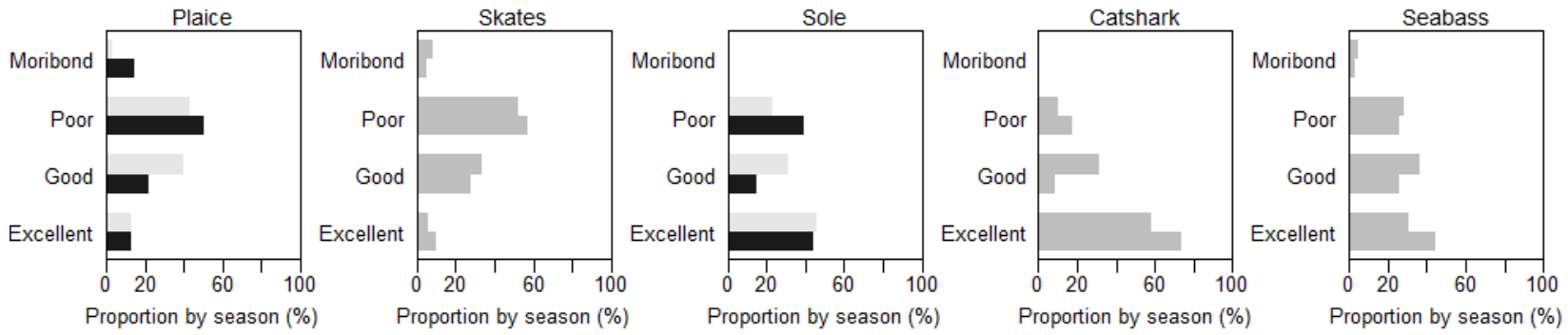
Figure 3: SQA index distribution by season with the bars for March appearing above those for July for each category. Bars are coloured according to season when the difference between seasons was significant, light grey for March and black for July, and otherwise coloured grey for both seasons.

For all species, RI and SQA indices were strongly correlated, with correlation coefficients ranging from 0.56 for catshark to 0.8 for plaice (Fig. 4). The RI score values barely overlapped between the adjacent SQA

212 levels, except the 'Excellent' and 'Good' groups for both sole and seabass. Also, for the five species, the

213 'Poor' group corresponded with the widest interval of RI score values. The RI scores ranged between 0 and

2140.25 in the 'Excellent' group, with 95\% lower or equal to 0.125 (1/8), corresponding to injured fish (Fig. 4).

215 These injuries were minor as defined in section 2.2, and did not affect the reflexes as the RI score in this 216 category rarely exceeded 1/8. Consistent with the 'Moribund' category definition (section 2.2), none of 217 these fish responded to any of the five reflexes tested. In accordance with the results above (Fig. 3), the 218 RI score distribution and composition were more species-dependent in the intermediate 'Good' and 'Poor' 219 groups (Fig. 4).

220
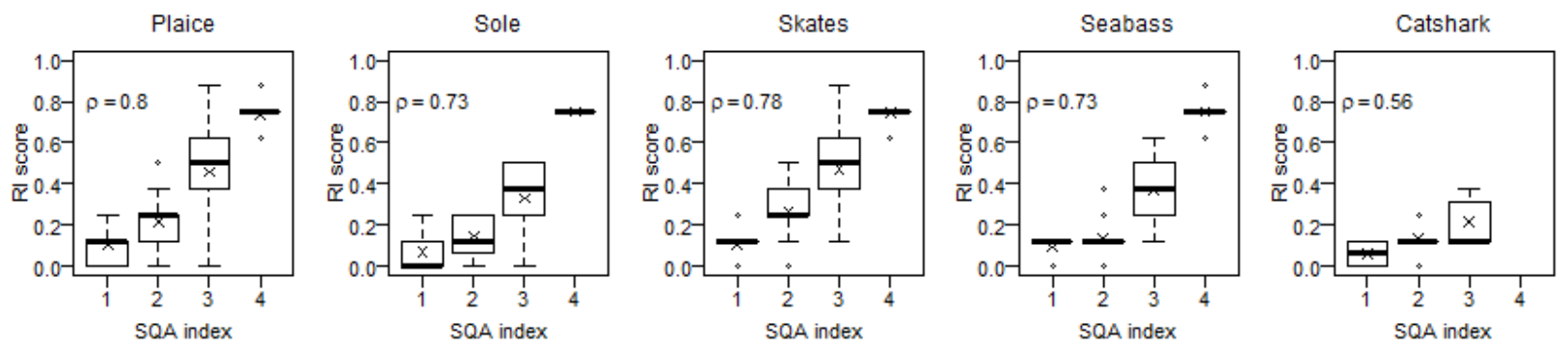

222 Figure 4. Distribution of the RI score as a function of the SQA index (1: 'Excellent', 2: 'Good', 3: 'Poor', 4:

223 'Moribond') for each species. Crosses are the mean scores, bands inside the boxes are the medians, boxes

224 limits are the first and third quartiles, and the whiskers have a length of $1.5 x$ the interquartile range. $\rho$ is the Spearman correlation coefficient.

\subsection{Correlates of the vitality indices}

227

The strength of the relationship between the vitality indices and the fishing conditions was quantified by

228 the percentages of deviance explained by the covariates tested in the regression models (Table 3). Overall,

229 the percentages were low, which may be due to the small contrast among the fishing conditions (Table 1),

230 but also to the robustness of these species. Indeed, the most important reported influential factors for

231 these species were related to the gear or mesh size (Enever et al., 2010), or at much larger ranges 
232 conditions of tow durations (Depestele et al., 2014; Enever et al., 2009) or air exposure (Methling et al., 233 2017). Furthermore, the levels of deviance explained were consistent with the relative survival potential 234 of the species which has been assessed independently (from catshark, followed by skates, sole, plaice, and 235 seabass; Morfin et al., 2017b), as the species with an intermediate survival potential are expected to be 236 more sensitive to external conditions than the species highly resistant or poorly resistant.

237 Higher levels of explained deviance were obtained for RI score compared to SQA, for all species except 238 skates. This result was expected as the SQA index was less detailed (four levels versus nine levels for RI) 239 and thus less prone to reflect the whole variability of the stressing factors. Nevertheless, more covariates 240 were systematically selected with SQA and the predictive performances were similar between SQA and RI 241 score. When looking at the response to correlates of each reflex and injury individually, they were together 242 responsive to more correlates than SQA index. This suggests that their score was not always meaningful 243 as some reflexes and injuries were not responsive or redundant, adding unnecessary variability (Fig. 2). 244 Davis, (2010) stressed that reflexes are species dependent and should be selected through assay validation 245 and stressor experiments under laboratory conditions. In this study the reflexes were preliminary tested 246 in an aquarium setting on unstressed individuals, but a necessary compromise was made to select a 247 combination of reflexes appropriate for all species.

248 However, the correlates were consistently related to both indices, reflecting their strong covariance, and 249 appeared clearly species dependent. Even the two flatfish were sensitive to different factors, sole was 250 significantly more impaired after longer tows while plaice was not. Van Beek et al., (1990) had found this 251 same phenomenon with beam trawling. Skates and plaice were sensitive to the presence of mud or mucus 252 in the catch, while catshark was apparently insensitive to any of the stress factors. The seabass was the 253 most sensitive to air exposure, followed by plaice, skates, sole and catshark, in accordance with Morfin et 254 al., (2017b) except for plaice which was less resistant than seabass according to these authors.

255 According to the SQA index, smaller skates and larger seabass were more sensitive to hypoxia. It has often 256 been reported that larger specimens were more resistant to the capture and handling processes (Benoît 257 et al., 2013; Revill et al., 2013; Uhlmann et al., 2016) and the opposite is much more unusual (see Methling 258 et al., 2017). However, the negative and important association of sole vitality with TL is very surprising and 259 suggests that the sole movement and response to stimuli may be dependent of the sole length, 260 independently of its vitality. In this case, the indices would not be a good predictor of survival, unless their 261 relationship to survival is calibrated as a function of the fish length. 


\begin{tabular}{|c|c|c|c|c|c|c|c|c|c|c|c|}
\hline & & $\%$ RPS & \%ExDev & Depth & Catch & $\begin{array}{c}\text { Tow } \\
\text { duration }\end{array}$ & $\begin{array}{l}\text { Injury- } \\
\text { inducing } \\
\text { elements }\end{array}$ & TL & $\begin{array}{c}\text { Thermal } \\
\text { Shock }\end{array}$ & $\begin{array}{c}\text { Thickler } \\
\text { Chain }\end{array}$ & $\begin{array}{c}\text { Air } \\
\text { exposure }\end{array}$ \\
\hline \multirow{2}{*}{ Sole } & $\mathrm{RI}$ & 28 & 29 & $+(3 \%)$ & $-(4 \%)$ & $+(11 \%)$ & $+(0.1)$ & $+(22 \%)$ & $+(3 \%)$ & $+(2 \%)$ & $+(0.1 \%)$ \\
\hline & SQA & 23 & 15 & $+(1 \%)$ & - (1\%) & $+(5 \%)$ & $+(0.3 \%)$ & $+(9 \%)$ & $+(1 \%)$ & $+(1 \%)$ & $+(0.1 \%)$ \\
\hline \multirow{2}{*}{ Catshark } & $\mathrm{RI}$ & 0 & 0 & $+(2 \%)$ & $+(3 \%)$ & $+(0.03 \%)$ & $-(1 \%)$ & $-(1 \%)$ & 0 & $+(5 \%)$ & $+(0.2 \%)$ \\
\hline & SQA & 0 & 0 & $-(0.1 \%)$ & - (0.4\%) & - (1\%) & $+(0.01 \%)$ & $-(0.02 \%)$ & $-2 \%$ & $+(0.01)$ & $-(0.1 \%)$ \\
\hline \multirow{2}{*}{ Seabass } & $\mathrm{RI}$ & 13 & 14 & $-(2 \%)$ & $+(3 \%)$ & $+(0.03 \%)$ & $+(2 \%)$ & $-(0.1 \%)$ & $-(5 \%)$ & NA & $+(11 \%)$ \\
\hline & SQA & 11 & 7 & $+(0.3 \%)$ & $+(2 \%)$ & $+(0.1 \%)$ & $+(0.5)$ & $-(0.3 \%)$ & $-(1 \%)$ & NA & $+(3 \%)$ \\
\hline \multirow{2}{*}{ Skates } & $\mathrm{RI}$ & 5 & 5 & $+(1 \%)$ & $+(1 \%)$ & $+(3 \%)$ & $+(5 \%)$ & $-(0.2 \%)$ & $-(0.01)$ & $+(1 \%)$ & $+(1 \%)$ \\
\hline & SQA & 5 & 7 & $+(1 \%)$ & $+(0.4 \%)$ & $+(1 \%)$ & $+(1 \%)$ & $-(0.2 \%)$ & 0 & $+(1 \%)$ & $+(1 \%)$ \\
\hline \multirow{2}{*}{ Plaice } & $\mathrm{RI}$ & 25 & 21 & $+(13 \%)$ & $+(0.02 \%)$ & $+(4 \%)$ & $+(8 \%)$ & $+(0.02 \%)$ & $+(2 \%)$ & $+(12 \%)$ & $+(5 \%)$ \\
\hline & SQA & 20 & 14 & $+(7 \%)$ & $-(0.2 \%)$ & $+(1 \%)$ & $+(7 \%)$ & $+(0.01 \%)$ & $+(2 \%)$ & $+(7 \%)$ & $+(2 \%)$ \\
\hline
\end{tabular}

Table 3. Results from the logit proportional models. In bold are the factors selected by AIC. +/- symbols designate the trend of the relationship between the index and the covariate. \%ExDev is the percentage of deviance explained by the covariates selected and was also calculated for each factor independently (between brackets) to assess their respective contribution. \%RPS is the percentage of RPS improvement of the selected model 
Most of the variability within indices was found between individuals of the same hauls rather than between the hauls or trips or seasons. This suggests that the fish were substantially subjected to unmeasured stress factors related to the capture process such as their position in the codend or the actual duration the fish endures in the tow, or perhaps to their biological conditions such as the sex or the reproduction status (Enever et al., 2009), although most of the discarded individuals were immature.

\section{CONCLUSION}

275

The reflexes and injuries approach is interesting as it inspects more thoroughly the different types of stresses the fish have experienced during the entire capture and discarding processes. Indeed, when looking at the different reflexes and injuries individually, they were sensitive to different stressing factors. Nevertheless, its scores were not responsive to the same diversity of external factors as the SQA index and displayed comparable predictive power. Accounting for injuries is clearly useful but the score could have been more consistent and sensitive with an additional intermediate injury level. The SQA index, based on a quick and general assessment of the fish activity and injuries, was highly correlated to the RI score for five different species. The SQA can thus be considered as useful a proxy of discard mortality as RI scores, with the advantage that it can be observed very rapidly and could be used on a routine basis to collect large samples in a wide variety of external conditions. Furthermore, because the SQA involves less manipulation of fish, it is less likely to induce additional stress that could induce a positive bias in estimated mortality. Finally, this study compared two indices based on their correlation and relationship with correlates. The obvious next step is to compare their predictive skills with respect to discard mortality. Ideally, this would be done in situ, for example using methods like Capizzano et al. (2016), where reflex impairment can affect the ability to evade predators (Olla and Davis, 1989; Olla et al., 1995), a potentially very important source of mortality for fish discarded in fisheries.

\section{Acknowledgements}

This work was part of the ENSURE project supported by France Filière Pêche and the Direction des Pêches Marines et de l'Aquaculture. The authors thank the crew of Déesses de l'Océan for their help on board to conduct the experiments. They also thank Camille Vogel and Fabien Morandeau for their help onboard the fishing vessels.

\section{References}

Barkley, A.S., and Cadrin, S.X. (2012). Discard Mortality Estimation of Yellowtail Flounder Using Reflex Action Mortality Predictors. Trans. Am. Fish. Soc. 141, 638-644. 
Benoît, H.P., Hurlbut, T., and Chassé, J. (2010). Assessing the factors influencing discard mortality of demersal fishes using a semi-quantitative indicator of survival potential. Fish. Res. 106, 436-447.

Benoît, H.P., Hurlbut, T., Chassé, J., and Jonsen, I.D. (2012). Estimating fishery-scale rates of discard mortality using conditional reasoning. Fish. Res. 125-126, 318-330.

Benoît, H.P., Plante, S., Kroiz, M., and Hurlbut, T. (2013). A comparative analysis of marine fish species susceptibilities to discard mortality: effects of environmental factors, individual traits, and phylogeny. ICES J. Mar. Sci. J. Cons. 70, 99-113.

Braccini, M., Rijn, J.V., and Frick, L. (2012). High Post-Capture Survival for Sharks, Rays and Chimaeras Discarded in the Main Shark Fishery of Australia? PLOS ONE 7, e32547.

Breen, M., Isaksen, B., Ona, E., Pedersen, A.O., Pedersen, G., Saltskår, J., Svardal, B., Tenningen, M., Thomas, P.J., Totland, B., et al. (2012). A review of possible mitigation measures for reducing mortality caused by slipping from purse-seine fisheries. ICES CM 100, 12.

Campbell, M.D., Patino, R., Tolan, J., Strauss, R., and Diamond, S.L. (2009). Sublethal effects of catchand-release fishing: measuring capture stress, fish impairment, and predation risk using a condition index. ICES J. Mar. Sci. 67, 513-521.

Capizzano, C.W., Mandelman, J.W., Hoffman, W.S., Dean, M.J., Zemeckis, D.R., Benoît, H.P., Kneebone, J., Jones, E., Stettner, M.J., Buchan, N.J., et al. (2016). Estimating and mitigating the discard mortality of Atlantic cod (Gadus morhua) in the Gulf of Maine recreational rod-and-reel fishery. ICES J. Mar. Sci. J. Cons. fsw058.

Christensen, R.H.B. (2015). ordinal - Regression Models for Ordinal Data.

Davis, M.W. (2010). Fish stress and mortality can be predicted using reflex impairment. Fish Fish. 11, $1-11$.

Depestele, J., Desender, M., Benoît, H.P., Polet, H., and Vincx, M. (2014). Short-term survival of discarded target fish and non-target invertebrate species in the "eurocutter" beam trawl fishery of the southern North Sea. Fish. Res. 154, 82-92.

Ellis, J.R., McCully Phillips, S.R., and Poisson, F. (2017). A review of capture and post-release mortality of elasmobranchs. J. Fish Biol. 90, 653-722.

Enever, R., Catchpole, T.L., Ellis, J.R., and Grant, A. (2009). The survival of skates (Rajidae) caught by demersal trawlers fishing in UK waters. Fish. Res. 97, 72-76.

Enever, R., Revill, A.S., Caslake, R., and Grant, A. (2010). Discard mitigation increases skate survival in the Bristol Channel. Fish. Res. 102, 9-15.

Epstein, E.S. (1969). A Scoring System for Probability Forecasts of Ranked Categories. J. Appl. Meteorol. 8, 985-987.

European Commission (2013). European Council Regulation (EU) No 1380/2013 of the European Parliament and of the Council of 11 December 2013 on the Common Fisheries Policy, amending Council Regulations (EC) No 1954/2003 and (EC) No 1224/2009 and repealing Council Regulations (EC) No 2371/2002 and (EC) No 639/2004 and Council Decision 2004/585/EC. Off. J Eur Union L 354. 
Hueter, R.E., and Manire, C.A. (1994). Bycatch and catch-release mortality of small sharks in the Gulf coast nursery grounds of Tampa Bay and Charlotte Harbor.

Humborstad, O.-B., Davis, M.W., and Lokkeborg, S. (2009). Reflex impairment as a measure of vitality and survival potential of Atlantic cod (Gadus morhua). Fish. Bull. 107, 395-402.

ICES (2014). Report of the Workshop on Methods for Estimating Discard Survival (WKMEDS) (ICES HQ, Copenhagen, Denmark).

Lewin, W.-C., Strehlow, H.V., Ferter, K., Hyder, K., Niemax, J., Herrmann, J.-P., and Weltersbach, M.S. (2018). Estimating post-release mortality of European sea bass based on experimental angling. ICES J. Mar. Sci. 75, 1483-1495.

Mandelman, J.W., Cicia, A.M., Ingram Jr., G.W., Driggers III, W.B., Coutre, K.M., and Sulikowski, J.A. (2013). Short-term post-release mortality of skates (family Rajidae) discarded in a western North Atlantic commercial otter trawl fishery. Fish. Res. 139, 76-84.

McCullagh, P. (1980). Regression Models for Ordinal Data. J. R. Stat. Soc. Ser. B Methodol. 42, 109142.

Mérillet, L., Kopp, D., Morandeau, F., Méhault, S., Rimaud, T., and Piton, C. (2017). Assessment of the survival rate of unwanted catches of Norway lobster Nephrops norvegicus caught by bottom trawling in the Bay of Biscay (IFREMER).

Mérillet, L., Méhault, S., Rimaud, T., Piton, C., Morandeau, F., Morfin, M., and Kopp, D. (2018). Survivability of discarded Norway lobster in the bottom trawl fishery of the Bay of Biscay. Fish. Res. 198, 24-30.

Methling, C., Skov, P.V., and Madsen, N. (2017). Reflex impairment, physiological stress, and discard mortality of European plaice Pleuronectes platessa in an otter trawl fishery. ICES J. Mar. Sci.

Morfin, M., Kopp, D., Benoît, H.P., Méhault, S., Randall, P., Foster, R., and Catchpole, T. (2017a). Survival of European plaice discarded from coastal otter trawl fisheries in the English Channel. J. Environ. Manage. 204, 404-412.

Morfin, M., Méhault, S., Benoît, H.P., and Kopp, D. (2017b). Narrowing down the number of species requiring detailed study as candidates for the EU Common Fisheries Policy discard ban. Mar. Policy $77,23-29$.

Nguyen, V.M., Martins, E.G., Robichaud, D., Raby, G.D., Donaldson, M.R., Lotto, A.G., Willmore, W.G., Patterson, D.A., Farrell, A.P., Hinch, S.G., et al. (2014). Disentangling the Roles of Air Exposure, Gill Net Injury, and Facilitated Recovery on the Postcapture and Release Mortality and Behavior of Adult Migratory Sockeye Salmon (Oncorhynchus nerka) in Freshwater. Physiol. Biochem. Zool. 87, 125-135.

Olla, B.L., and Davis, M.W. (1989). The role of learning and stress in predator avoidance of hatcheryreared coho salmon (Oncorhynchus kisutch) juveniles. Aquaculture 76, 209-214.

Olla, B.L., Davis, M.W., and Schreck, C.B. (1995). Stress-induced impairment of predator evasion and non-predator mortality in Pacific salmon. Aquac. Res. 26, 393-398.

Raby, G.D., Donaldson, M.R., Hinch, S.G., Patterson, D.A., Lotto, A.G., Robichaud, D., English, K.K., Willmore, W.G., Farrell, A.P., Davis, M.W., et al. (2012). Validation of reflex indicators for measuring 
377 vitality and predicting the delayed mortality of wild coho salmon bycatch released from fishing gears.

378 J. Appl. Ecol. 49, 90-98.

379 Raby, G.D., Packer, J.R., Danylchuk, A.J., and Cooke, S.J. (2014). The understudied and

380 underappreciated role of predation in the mortality of fish released from fishing gears. Fish Fish. 15,

$381 \quad 489-505$.

382 Revill, A.S., Dulvy, N.K., and Holst, R. (2005). The survival of discarded lesser-spotted dogfish

383 (Scyliorhinus canicula) in the Western English Channel beam trawl fishery. Fish. Res. 71, 121-124.

384 Revill, A.S., Broadhurst, M.K., and Millar, R.B. (2013). Mortality of adult plaice, Pleuronectes platessa and sole, Solea solea discarded from English Channel beam trawlers. Fish. Res. 147, 320-326.

Ridgway, I.D., Taylor, A.C., Atkinson, R.J.A., Chang, E.S., and Neil, D.M. (2006). Impact of capture method and trawl duration on the health status of the Norway lobster, Nephrops norvegicus. J. Exp. Mar. Biol. Ecol. 339, 135-147.

Rodríguez-Cabello, C., Fernández, A., Olaso, I., and Sánchez, F. (2005). Survival of small-spotted catshark (Scyliorhinus canicula) discarded by trawlers in the cantabrian sea. Mar. Biol. Assoc. U. K. J. Mar. Biol. Assoc. U. K. Camb. 85, 1145-1150.

Stoner, A.W. (2009). Prediction of discard mortality for Alaskan crabs after exposure to freezing temperatures, based on a reflex impairment index. Fish. Bull. 107, 451-463.

Uhlmann, S.S., Theunynck, R., Ampe, B., Desender, M., Soetaert, M., and Depestele, J. (2016). Injury, reflex impairment, and survival of beam-trawled flatfish. ICES J. Mar. Sci. J. Cons. fsv252.

Van Beek, F.A., Van Leeuwen, P.I., and Rijnsdorp, A.D. (1990). On the survival of plaice and sole discards in the otter-trawl and beam-trawl fisheries in the North Sea. Neth. J. Sea Res. 26, 151-160.

Wilks, D.S. (2011). Statistical methods in the atmospheric sciences (Academic press). mortality of summer flounder (Paralichthys dentatus) in the commercial trawl fishery: Developing

401 acoustic telemetry techniques. Fish. Res. 115, 72-81.

402 Yochum, N., Rose, C.S., and Hammond, C.F. (2015). Evaluating the flexibility of a reflex action mortality predictor to determine bycatch mortality rates: A case study of Tanner crab (Chionoecetes baird) bycaught in Alaska bottom trawls. Fish. Res. 161, 226-234. 